\title{
Межличностные отношения в полиэтничном трудовом коллективе в условиях реорганизации
}

(C) 2019 Шумилкина Евгения Александровна*,

*начальник начальник научно-исследовательского отдела ФГБОУ ВО «Пензенский государственный университет» (г. Пенза, Россия), jany22@rambler.ru

Электронный научный журнал «Пензенский психологический вестник» (ISSN 2312-7392) 2019 №2(13):25-32; DOI: 10.17689/psy-2019.2.3

Анотация: В статье содержатся результаты теоретического анализа работ, посвященных проблеме межличностных отношений, опосредованных спецификой этнического состава и организационными изменениями. Представлены результаты полуструктурированного интервью 300 сотрудников моно и полиэтничных трудовых коллективов торговопромышленных предприятий Пензенского региона, в ходе которого изучалось их отношение к реструктуризационным изменениям в организации.

Ключевые слова: межличностные отношения, моно и полиэтничные трудовые коллективы, организационные изменения

(http://www.psychology-news.ru/2019/2-3)

Межличностные взаимодействия имеют основополагающее значение для нашей жизни и являются основой не только повседневной жизни человека, но и определяют условия труда, формируют климат в коллективе. Межличностные отношения формируются в определенных условиях, которые влияют на их динамику, широту и глубину [3]. Чем чаще люди встречаются, тем позитивнее окрашены межличностные отношения между ними и наоборот. Общение на работе являются источником душевного благополучия человека. Социально-психологический климат рабочей среды определяет, степень продуктивности труда и активность сотрудника, мотивированность, продолжительность работы сотрудника в данной организации, независимо от того, участвует ли он в принятии организационно-экономических решений или нет, поддерживает ли управленческий курс, 
и ценит ли цель и стратегию развития организации. Межличностные отношения - это «дверь» в то, как мы ведем себя, чувствуем и думаем на работе [2].

Межличностные отношения являются ключевой частью структуры организационной жизни. Рабочий процесс по своей сути реляционно связан с межличностными отношениями сотрудников внутри коллектива, играющими существенную роль в развитии жизнеспособной и продуктивной «трудовой жизни» [4]. Опыт, реакция и принимаемые решения в процессе деятельности организации находятся под влиянием и формируются посредством взаимодействия с другими членами коллектива, которые встречаются как на рабочем месте, так и за его пределами [5].

Профессиональные (трудовые) межличностные отношения важны для изучения, потому что они могут оказывать сильное влияние на поведение сотрудников, а, следовательно, и на эффективность деятельности предприятия в целом. Научными данными подтверждено, что позитивные реляционные взаимодействия на работе связаны с более благоприятным отношением к работе, снижением напряжения, и даже благоприятным самочувствием сотрудников $[6,7]$. С другой стороны отрицательные реляционные взаимодействия в трудовом коллективе провоцируют негативные реакции со стороны сотрудников, снижают благополучное сосуществование и приводят к деформации системы [6].

Современные организации в России - это, в большинстве своем, полиэтнические сообщества, как в исполнительской структуре, так и в органах управления, что обусловлено историческим прошлым. Наша страна «никогда не была русским государством, уже на заре своего существования в период Киевской Руси она представляла собою полиэтническое образование и, развиваясь, продолжала отторгать модель национального государства, наиболее распространенную в современном мире» [1].

Социально-психологическая сплоченность членов коллектива отражает мнение человека о себе по отношению к другим людям в социальном контексте. Когда чувство сплоченности уменьшается, человек начинает чувствовать себя далеким и отличным от других людей и начинает противопоставлять себя коллективу [8]. Степень сплоченности коллектива является предиктором негативного восприятия сотрудником рабочего процесса, в том числе членов коллектива и ассимиляционного стресса среди этнического меньшинства [9].

Сотрудники, попавшие в условия, где большая часть коллектива представлена членами одной этнической группы либо теряют связь с «корнями», либо начинают активнее проявлять этническую принадлежность той или иной культуре, что в обоих случаях может представлять угрозу, как для психического состояния самого сотрудника, так и для 
социально-психологического климата в организации в целом. Естественно, работа в полиэтническом трудовом коллективе - это обоюдоострый опыт, как для этнического большинства, так и представителей малых этнических групп.

С одной стороны, люди, находящиеся в мультикультурной среде, могут получить положительный опыт общения и перенять черты поведения, которые в процессе работы могут благоприятно сказаться на рабочем процессе и использоваться при общении за пределами коллектива, либо при деловом общении с партнерами представителями данной этнической группы. С другой стороны, нахождение в мультикультурной среде может привести к проблемам ассимиляции, таким как чувство отвержения в разных культурных контекстах [10]. Причем, не только меньшинство может испытывать проблемы с адаптацией к среде, но и представители культурного большинства тоже должны адаптироваться к новым условиям.

С учетом вышесказанного, нами была предпринята попытка изучения особенностей межличностных отношений в полиэтнических трудовых коллективах в условиях реорганизации. Сбор информации осуществлялся в ходе полуструктурированных интервью испытуемых по месту работы. Исследование проводилось нами среди 300 сотрудников торгово-промышленных предприятий Пензенской области (ООО «Торговый дом «Петелино Поволжье», ООО «Черкизово-Пенза», ООО ПКФ «Гранит-М») в большей степени (70\%) представленных специалистами среднего звена.

В ходе структурированных интервью была собрана информация об отношении сотрудников организаций к реструктуризационным изменениям в организации.

На основании результатов субъективного отношения сотрудников организаций очень четко выделяются 3 группы реакций на изменения.

Большая часть респондентов (55\% опрошенных) заняла категорически отрицательную позицию в отношении структурных изменений в организации. Причем, данная позиция прослеживается как у сотрудников среднего звена, так и у занимающих руководящие должности:

- Сергей (50 лет, монтажник): На утренней летучке начальник огорошил. Нашу фирму ждет реорганизация. Мол, покрылись мы все пылью и плесенью, а клиенты хотят чего-то свежего и креативного. Причем виноваты в сложившейся ситуации, конечно, мы рядовые сотрудники, а никак не руководство. Хорошая новость - всем работникам пообещали поднять процент от оклада, плохая - скорее всего, грядут сокращения. Хотя вслух об этом сказано не было. По слухам, на дверь укажут тем, у кого нет высшего образования и этот как раз я. И неважно, что я отдал фирме почти 30 лет, такой квалификации и опыта, нет ни у кого в нашей организации. Да, когда-то я не пошел 
учиться в вуз, предпочтя техникум, но кто же знал, что в будущем это разрушит мою дальнейшую карьеру!?

- Вадим (44 год, руководитель службы безопасности): Недавно узнал, что компании предстоит реорганизация. Я мужчина за 40 , занимаю руководящую должность и отдаю себе отчет, что вряд ли останусь на своем месте. Поэтому, к данной новости отношусь крайне негативно. Изменится структура и состав руководящего аппарата, а значит, новое руководство будет набирать свою команду, что совершенно не придает уверенности мне в завтрашнем дне.

- Дмитрий (34 лет, сотрудник отдела продаж): в этой компании работаю недавно, но даже за такой короткий срок у нас уже второй раз меняется начальник. Теперь на это место поставили Раиля Фаритовича. Не прошло и пары месяцев как он начал подтягивать «своих». У нас и так была напряженная обстановка в отделе, а теперь и подавно. Видимо пора искать новую работу.

Меньшая по численности группа, но тоже преобладающая (35\%) это нейтральная позиция «делайте, что хотите, только нас не трогайте»:

- Рушан (29 лет, сотрудник оптового склада): Я простой работяга и что там происходит с организацией и руководством мне все равно. Главное, чтобы предстоящая реорганизация не коснулась нас. Надеюсь, конечно, на лучшее. Ну изменится название, может даже руководство. Как говорят, собственник у нас в Москве и хотят сократить именно управленцев.

- София (41 лет, старший менеждер): Зачем мне изменения? Я не хочу ничего менять! Может быть будет и лучше, а может быть и хуже. Я уже пережила одну реструктуризацию в этой организации. Тогда это закончилось положительными изменениями. Что будет в этот раз, не знаю. Надеюсь на повторение предыдущего сценария.

Самая маленькая группа опрошенных (10\%) считает, что изменения приведут к положительным изменениям и позитивно оценивают ситуацию:

- Евгения (32 года, сотрудник отдела продаж): Я очень рада, что у нас, наконец, произойдут изменения. Мы долго этого ждали, т.к. это приведет к увеличению объемов продаж, а, следовательно, и к увеличению наших заработков. И я постараюсь сделать максимум, что в моих силах, чтобы помочь нашей фирме.

По результатам интервью сотрудников организации условно можно разделить на два типа. Первый - «жертвы ситуации» это люди, которые думают, что они обязательно пострадают, и поэтому сопротивляются изменениям, выражают недовольство и агрессию. 
Таких респондентов преобладающее большинство. Второй тип - люди, которые полностью поддерживают перемены, разрабатывают и планируют изменения.

Отвечая на поставленный ранее вопрос можно сказать, что распространенность отрицательного восприятия реорганизационных процедур среди полиэтнического трудового коллектива приблизительно одинакова как среди этнического большинства, так и среди представителей малых этнических групп и в большей мере зависит от культурных особенностей и менталитета конкретной нации, социального положения данного сотрудника и его возраста. Также подтвердилась гипотеза о том, что тесные связи внутри трудового коллектива способствует большему чувству уверенности в благополучном завершении изменений в организации. Более сильное чувство связи с другими людьми позволит человеку чувствовать себя более комфортно и уверенно в социальном контексте.

Некоторые сотрудники организации боятся изменений и противятся им всем своим естеством, так как перемены оказывают сильное влияние и даже давление на взгляды, мнения и убеждения, укоренившиеся в их сознании. Часто это является результатом неудачного жизненного опыта, связанного с деятельностью по осуществлению перемен.

\section{Литература:}

[1] Сикевич 3. В. (1999). Социология и психология национальных отношений: Учебное пособие. СПб.: Изд- во Михайлова В. А., 1999.

[2] Eduardo Salas, Series Foreword. (2012). In Personal Relationships. The Effect on Employee Attitudes, Behavior, and Well-being; de Tormes Eby, L.T., Allen, T.D., Eds.; Taylor \& Francis Group: East Sussex, UK; New York, NY, USA, 2012.

[3] Росс Л., Нисбет Р. (2000). Человек и ситуация: уроки социальной психологии. - М., 2000.

[4] Cropanzano, R., \& Mitchell, M. S. (2005). Social exchange theory: An interdisciplinary review. Journal of Management, 31, 2005.

[5] Blustein, D. L. (2011). A relational theory of working. Journal of Vocational Behavior, 79, 2011.

[6] Grant, A. R., \& Parker, S. K. (2009). Redesigning work design theories: The rise of relational and proactive perspectives. Academy of Management Annals, 3, 2009. 
[7] Dutton, J. E., \& Ragins, B. R. (2007). Exploring positive relationships at work: Building a theoretical and research foundation. Mahwah, NJ: Lawrence Erlbaum Associates, 2007.

[8] Lee, R.M.; Robbins, S.B. (1995). Measuring belongingness: The Social Connectedness and the Social Assurance scales. J. Couns. Psychol., 42, 1995.

[9] Williams, K.L.; Galliher, R.V. (2006). Predicting Depression and Self-Esteem from Social Connectedness, Support, and Competence. J. Soc. Clin. Psychol. 25, 2006.

[10 Pekerti, A.A.; Vuong, Q.H.; Napier, N.K. (2017). Double edge experiences of expatriate acculturation: Navigating through personal multiculturalism. J. Glob. Mobil. 5, 2017. 